\title{
Phonotactic Behavior of Female Sagebrush Crickets
}

\author{
SCOTT K. SAKALUK \\ DePartment of Biological ScIENCES — Illinois State University \\ NORMAL, IL \\ W. ANDREW SNEDDEN \\ DePartment of ZoOlogy, ERINDAle College $\downarrow$ University of Toronto \\ Mississauga, Ontario $\uparrow$ CANADA
}

\section{$\downarrow \quad$ INTRODUCTION}

The Prophalangopsidae is an ancient insect family with fossil records dating back to the Jurassic period, approximately 180 million years ago (Vickery 1989). The family is believed to be ancestral to the ensiferan Orthoptera (crickets and katydids), a diverse and economically important group of insects (Morris \& Gwynne 1978). Although fossil records indicate that the Prophalangopsidae was once a diverse, widely distributed and abundant group of insects, the family is now nearly extinct. It is represented in North America by a single relict genus (Cyphoderris) containing three species, by a single species in the Soviet Far East, and by a single species in India that is known only by a single specimen (Vickery 1989). By way of contrast, an allied family, the Gryllidae (true crickets), contains over 2600 species worldwide, distributed across 14 subfamilies (Walker 1989).

The decline of the Prophalangopsidae is poorly understood, although climatic changes accompanying the Pleistocene glaciation are considered one possible factor (Vickery 1989). The three extant North American species occur only in the western US and Canada. One of these, the sagebrush cricket
(Cyphoderris strepitans), is known only from a few mountainous areas in Wyoming and Colorado, including Grand Teton National Park (Morris \& Gwynne 1978). Despite the prevalence and apparent homogeneity of the sagebrush-dominated habitat within which $C$. strepitans occurs, sagebrush crickets are patchily distributed within GTNP (pers. obs.), perhaps owing to their low vagility (sagebrush crickets are cumbersome walkers lacking flight ability) and/or to restrictive microhabitat requirements. Intensive studies concerning the natural history, population biology and behavioral ecology of sagebrush crickets have been ongoing in GTNP since 1978 when the species was first named (e.g., Morris \& Gwynne 1978, Dodson et al. 1983, Sakaluk et al. 1987, Morris et al. 1989, Sakaluk \& Snedden 1990). In recent work, we have attempted to identify the selective forces contribution to the evolution of the species' unique mating system and life history.

In Grand Teton National Park, adult $C$. strepitans become sexually active at an unusually early and hence unseasonable time of year (early May) and remain active only for a short 4-6 week period. Each night of the breeding season, males emerge from the soil litter shortly after sunset, climb into the sagebrush and begin 
to sing, presumably to attract sexually receptive females. Copulation is initiated when a receptive female climbs onto the dorsum of a male, at which time he attempts to transfer a spermatophore. During the time that the female is mounted on the male, she feeds on the male's metathoracic wings and ingests any hemolymph oozing from the wounds she inflicts (Dodson et al. 1983, Sakaluk et al. 1987).

A previous field study involving the mark-recapture of a large number of males showed that once a male had mated, his probability of obtaining additional copulations paradoxically was reduced (Morris et al. 1989). One explanation for this result is that non-virgin males, having lost a substantial portion of available energy reserves at mating, may be unable to sustain calling at pre-mating levels. In support of this hypothesis, electronic assays of male signaling behavior (see Kidder \& Sakaluk 1989) have shown that virgin male $C$. strepitans call for significantly longer durations than recently mated males (Sakaluk et al. 1987, Sakaluk \& Snedden 1990).

The above hypothesis assumes that females respond to the acoustic signals of males, such that males which call for longer durations attract more mates. We have been unable, however, to demonstrate female phonotaxis in standard behavioral bioassays (Morris et al. 1989). There are at least three hypotheses which could account for the observed lack of female responsiveness:

1. females are not phonotactic, but instead locate males via other signaling modalities (e.g., olfaction, substrate-transmitted vibrations),

2. females may exhibit phonotaxis only during a narrow time window or respond only under test conditions which closely approximate the field environment and

3. elicitation of a female response may require an extended period of auditory stimulation that exceeds the short response times expected of females in standard laboratory phonotaxis experiments (Sakaluk \& Snedden 1990).

The objectives of the present study were:

1. to seek evidence of female phonotaxis by comparing the subsequent mating success of experimentally muted males with that of untreated rivals and

2. to complete time-lapse video studies of mating interactions initiated in the 1989 field season.

\section{$\downarrow$ Methods}

\section{FIELd StUdy}

To test the hypothesis that females use the sounds of males to locate males as mates, a mark-recapture study was conducted in May-June, 1990 near the Snake River at Deadman's Bar in Grand Teton National Park. Four corners of a rectangular study plot $(90 \mathrm{~m} \times 60 \mathrm{~m})$ were staked out in a sagebrush meadow that was located on a bench of the river's flood plain. During four nights of sampling (May 17, 18, 21 and 22), we attempted to capture and mark all of the virgin males present in the study plot. Perching locations of males were found by orienting to the acoustic signals produced by individual males and then searching the sagebrush with the aid of a headlamp. Non-virgin males (as evidenced by wing wounding) were released at their point of capture immediately after their mating status had been ascertained. Each virgin male was placed in a numbered vial and transported to a processing table located at the study site, after their mating status had been ascertained. Each virgin male was placed in a numbered vial and transported to a processing table located at the study site, after its capture site had been marked with an identically numbered flag. Following experimental processing (see below), virgin males were released at their flagged capture sites, thereby preserving the original distribution of males and facilitating their subsequent recapture.

Captured males were sequentially assigned, in order of their capture, to one of three experimental groups:

1. experimentally muted,

2. sham control, and

3. unmanipulated.

Sequential assignment of males ensured that a comparable number of males in each group was marked on any one night, and that subsequent mating opportunities were equivalent across treatments. Moreover, this protocol ensured that the locations of experimental males, for each of the three treatments, were drawn at random. Males in Group 1 were rendered mute by surgically removing the file from each tegmen, an operation facilitated with the aid of a Wild M5A stereo-microscope. Removal of both files was required because males are capable of "switch-wing" singing, in which one or the other file is employed during stridulation (Morris \& Gwynne 1978). Males in Group 2 group had a portion of their 
tegmina removed comparable in area to that of Group 1 males, but distal to the sound-producing structures. The tegmina of Group 3 males were left unaltered. Males of each treatment were color coded by painting their pronota with Testor's fluorescent model paint (mute: blue or green, sham: yellow, unmanipulated: orange). We marked and released a total of 70 virgin males ( 24 mute, 23 sham and 23 unmanipulated).

Once we had marked the bulk of the virgin male population in our study plot, males were re-captured and examined for evidence of mating activity on four subsequent nights (May 26, 27, 28 and June 3). Experimental males were located by scanning the sagebrush and ground with portable UV lights, the illumination of which caused the painted pronota of experimental males to brightly fluoresce. Although the re-capture of sham and unmanipulated was aided further by orienting to their sounds, the number of males that were recaptured at least once was almost exactly the same for all three treatments (13 mute, 12 sham. 13 unmanipulated).

We recorded the following data for each male captured:

1. mating status, as determined by the condition of the hindwings (unwounded = virgin, wounded - non-virgin),

2. whether the male was marked (experimental) or unmarked (non-experimental), and

3. if marked, the treatment to which the male belonged.

When a marked male was recaptured, his right metathoracic femur was marked with pigmented nail polish if he was a virgin, and both femora were marked if he was a non-virgin. On subsequent sampling nights, therefore, we were able to record whether a marked male was a previous recapture, and ascertain his previous mating status. This protocol prevented us from counting any male more than once in the final recapture tally, and allowed us to determine whether a male has mated over successive recaptures.

The hypothesis predicts that the mating success of muted males should be significantly lower than that of sham-control or unmanipulated males. Alternatively, if females employ some other means of finding males (e.g., olfaction, vibratory signals), we would not expect any appreciable difference in male mating success across treatments.

\section{Time-LapSe Video STUdy}

To examine more closely the determinates of male mating success, a time-lapse video study was conducted in May-June 1989 and 1990. Male and female $C$. strepitans were captured at a study site located on top of an escarpment overlooking the Snake River at Dead Man's Bar in Grand Teton National Park. Because females are mute, they were found largely through chance encounters. Crickets were transported back to the research station where they were housed in plastic vials, provisioned every other day with a slice of apple.

Triadic mating interactions were staged in a plexiglass arena and recorded using a time-lapse video recorder (Panasonic AG-6050) and a camera equipped with a macro lens (Panasonic WV-3250/8AF). Each triad consisted of a virgin male a non-virgin male and a female of unknown mating status. All crickets were weighed prior to introduction into the arena. Each night of the study, a single triad was established at approximately 2000 hours at which time recording commenced. The video recorder was set to the $12-\mathrm{H}$ recording option; on this time mode, a single frame was recorded every 0.1 seconds. In total, we video-taped 43 triadic interactions (20 in 1989 and 23 in 1990) of which 30 resulted in matings (15 matings in each of 1989 and 1990). When a mating occurred, the participants involved in the interaction were never used again, thereby avoiding pseudo-replication of data.

Upon review of video-tape recordings of mating interactions, we recorded:

1. the number of mating opportunities for each male (as indicated by wing feeding behavior of the female and/or clamping of the female's abdomen by the male's abdominal pinching organ),

2. the frequency and duration of copulations,

3. the time spentcalling by each male and

4. the frequency and duration of spermatophore feeding by the female.

\section{Results}

\section{Field Study}

Of those marked males recaptured at least once, $2 /$ 13 muted males, $12 / 12$ sham-control males, and 12/13 
unmanipulated males had mated. Contingency table analysis showed that differences in male mating frequencies across treatments were statistically significant $\left(\chi^{2}=25.89, \mathrm{p}<0.001\right)$. The source of these differences was revealed by subdividing the chi-square analysis (Zar 1984). The mating frequency of muted males was significantly less than that of sham-control $\left(\chi^{2}=18.13, \mathrm{p}<0.001\right)$ and unmanipulated males $\left(\chi^{2}=\right.$ $15.48, \mathrm{p}<0.001)$. There was no significant difference in the mating frequency of sham-control and unmanipulated males $\left(\chi^{2}=0.96, \mathrm{p}<0.05\right)$.

The above analysis incorporates those instances in which the mating status of a male changed over successive recaptures. To provide a more conservative test of the null hypothesis, the data were re-analyzed using first-time recaptures only. Of those marked males recaptured for the first time, $1 / 13$ muted males, $10 / 12$ sham-control males, and 9/13 males had mated. As in the previous analysis, differences in male mating frequency across treatments were statistically significant $\left(\chi^{2}=16.50, \mathrm{p}<0.001\right)$. Pairwise comparisons revealed that the mating frequency of muted males was significantly lower than that of sham-control $\left(\chi^{2}=14.49, \mathrm{p}<0.001\right)$ and unmanipulated males $\left(\chi^{2}=10.40, \mathrm{p}<0.005\right)$. There was no significant difference in the mating frequency of sham-control and unmanipulated males $\left(\chi^{2}=0.41, \mathrm{P}\right.$ $>0.05$ ).

\section{Time-LAPSE Video STUdY}

Preliminary analyses using full-factor ANOVAs revealed that YEAR (the year in which triads were video-recorded) had no effect on any of the reproductive parameters measured. Consequently, data from 1989 and 1990 were combined in subsequent analyses. Means are given $\pm S E$.

\section{Mating FReQuenCy}

In the 30 interactions leading to copulation, the male to first mate with the female was designated the 'successful' male while the other male was designated 'unsuccessful'. Initial copulations occurred, on the average, $317.8 \pm 33.8$ minutes after the introduction of experimental individuals (range $=24-643 \mathrm{~min}$ ) and lasted, on the average, $272.3 \pm 19.2$ seconds (range = $120-595 \mathrm{sec})$. In 8 of the 30 interactions, two matings occurred during the recording interval; 4 of the second matings involved the successful male and 4 involved the unsuccessful male. Secondmatings by successful males occurred 107, 196, 245 and 447 minutes, respectively, after the first.

\section{Correlates of Male Mating Success}

\section{i Calling Duration}

Pre-copulatory calling durations of successful and unsuccessful males are shown in Table 1. The absolute difference in calling durations of successful and unsuccessful males covaried with the time at which the mating occurred $(r=0.66, p<0.0002)$; essentially, differences in pre-copulatory calling times increased as copulations occurred later in the night. This covariance was effectively eliminated by transforming calling durations to their $\log _{10}$ values $(r=$ $0.10, \mathrm{p}>0.05)$, thereby facilitating direct comparison of the calling times of successful and unsuccessful males. The analysis revealed that successful males called for a relatively longer duration prior to copulation than did unsuccessful males (paired t-test, one tailed, $\mathrm{t}=1.76, \mathrm{p}<0.05$ )

In 16 interactions, the successful male was the last to call before the copulation occurred versus 4 interactions in which the unsuccessful male was the

Table 1.Pre-copulatory calling durations of mated and unmated male $C$. strepitans in triadic interactions. Means are significantly different at $\mathrm{p}<0.025$ (paired $\mathrm{t}$-test, one-tailed, $\mathrm{t}=2.19$ ).

\begin{tabular}{lcccc}
\hline \hline & N & Mean $(\min )$ & SE & Range \\
\hline Mated & 30 & 170.4 & 25.5 & $0-447$ \\
Unmated & 30 & 127.5 & 23.1 & $3-559$ \\
\hline
\end{tabular}


last to call. This difference is statistically significant $\left(\chi_{\text {yates }}^{2}=6.05, p<0.025\right)$.

Calling did not always immediately precede a successful copulation. In 35 interactions, the successful male was calling immediately prior to copulation, but on 4 occasions the successful male had ceased calling $2,8,14$ and 47 minutes before copulation, respectively. On one occasion, the successful male did not call at all before mating, but was standing immediately adjacent to a calling (unsuccessful) male at the time the female mounted him.

\section{Mating OpPortunities}

Successful males experienced significantly more mating opportunities prior to copulation than did unsuccessful males $(2.13 \pm 0.39$ vs $0.77 \pm 0.30$, Wilcoxon paired sample test, $\mathrm{p}<0.0005)$. There was no significant difference, however, in the total number of mating opportunities experienced by successful and unsuccessful males over the entire $12-\mathrm{h}$ recording interval $(3.50 \pm 0.53$ vs $2.67+0.63, \mathrm{p}>0.05$ ).

\section{Mating Status}

Sixteen of the 30 successful males mated as virgins, and 14 mated as non-virgins. Mean calling durations of virgin males were longer than those of non-virgins (Table 2), but the difference in log-transformed calling times was only marginally significant (paired $\mathrm{t}$ test, one tailed, $\mathrm{t}=1.65, \mathrm{p}=$ $0.055)$. We also compared the frequency of matings by virgin males that were either the "high" caller or "low" caller in triadic interactions. Contingency table analysis revealed that high virgin callers achieved proportionally more matings than low callers (13/20 vs $3 / 10$ ), but this too was only marginally significant (log-likelihood ratio, $\mathrm{G}=3.34, \mathrm{p}-0.068$ ). There was no significant difference in the number of mating opportunities experienced by virgin and non-virgins prior tocopulation $(1.67 \pm 0.40$ vs $1.23 \pm 0.33$, p > $0.05)$, nor was there a difference in mating opportunities over the entire 12 -h recording period $(3.57 \pm 0.55$ vs $2.60 \pm 0.62, p>0.05)$.

\section{iv Male Body Size}

There was no significant difference in the wet mass of successful and unsuccessful males, nor in the mass of virgin and non-virgin males.

\section{Male-Male Competition}

No overt aggression was ever observed between males. Frequently, however, one male would mount the other an engage in wing feeding for a variable length of time. We observed 15 such homosexual mountings distributed over 9 interactions. In such cases, the mounted male would expose the underlying metathoracic wings and attempt genitalic contact in much the same manner as if he had been mounted by a female. Homosexual mountings were of variable duration and invariably terminated with the mounted male pulling away.

\section{Female Behavior}

Females frequently mounted males and engaged in wing feeding without receiving the spermatophore. Such 'opportunistic feedings' occurred in 24/30 interactions and at a variable frequency within interactions (range $=1-21$ ).

With one exception in which the spermatophore was dislodged against a wall of the chamber, females always consumed the spermatophore after mating; spermatophore consumption commenced, on the average, $168.46 \pm 25.0$ minutes after the initial copulation ( $\mathrm{n}=26$, range $=3-512 \mathrm{~min})$.

Table 2.Pre-copulatory calling durations of virgin and non-virgin male $C$. strepitans in triadic interactions. Means are significantly different at $\mathrm{p}<0.05$ (paired $\mathrm{t}$-test, one-tailed, $\mathrm{t}=1.94$ ).

\begin{tabular}{lcccc}
\hline \hline & $\mathrm{N}$ & Mean (min) & SE & Range \\
\hline Virgin & 30 & 165.80 & 24.98 & $6-433$ \\
Non-Virgin & 30 & 132.13 & 23.90 & $0-559$ \\
\hline
\end{tabular}




\section{Conclusions}

Our field experiment showed a marked decrease in the fitness of experimentally muted males, and we interpret this result as evidence of female phonotaxis. Alternatively, male calling theoretically could function as a territorial signal to other males, with females attracted to males via some other signaling modality (e.g., olfaction, substrate-transmitted vibrations). One could argue, therefore, that the decline in fitness of muted males comes from an inability to exclude rivals, rather than an inability to attract females. For this to be a plausible alternative, however, males would have to show evidence of territorial behavior, defending an area from which other calling males were actively. excluded. In contradiction of this prediction, we have observed male $C$. strepitans frequently calling from the same bush and, on a number of occasions, males have been observed calling side-by-side at the base of the same bush (pers. obs.). If calling functions as a territorial signal, it is remarkably ineffective. Moreover, males display none of the aggressive behaviors that characterize territorial Orthoptera. In close to 1000 hours of video recording of male-male interactions we have not observed a single instance of overt aggressive behavior, nor has such behavior ever been observed in the field. Males do, however, appear to hear and react acoustically to the signals of other males: silent males can be easily primed to call through playback of conspecific song (pers. obs.).

At least two lines of evidence from our video studies also support a mate-attracting function to male calling. First, in triadic interactions, males that called the most prior to matings had a significantly higher probability of acquiring the matings. Second, and perhaps more compelling, the last male to call prior to when the mating occurred, copulated more often than expected on the basis of chance. If females were attracted to males through olfaction, we would predict that whichever male was the last to call would have no bearing on the probability of that male mating. That it does, supports the female-phonotaxis hypothesis and negates the olfaction hypothesis. It is possible, of course, that sagebrush crickets possess pheromones that are employed in sexual recognition, as is true of a number of other ensiferan Orthoptera.

\section{Literature Cited}

Dodson, G. N., G. K. Morris, and D. T. Gwynne. 1983. Mating behavior of the primitive orthopteran genus Cyphoderris (Haglidae). pp. 305-318. In: Orthopteran Mating Systems: Sexual Competition in a Diverse Group of Insects, ed. by D. T. Gwynne and G. K. Morris. Westview Press, Boulder, CO.

Kidder, G. W. III, and S. K. Sakaluk. 1989. A simple and inexpensive electronic device for automatic recording and analysis of insect acoustical activity. Fla. Ent. 72:642-649.

Morris, G. K. 1979. Mating systems, paternal investment and aggressive behavior of acoustic Orthoptera. Fla. Ent. 62:9-17.

Morris, G. K., and D. T. Gwynne. 1978. Geographical distribution and biological observations of Cyphoderris (Orthoptera: Haglidae) with a description of a new species. Psyche 85:147-167.

Morris, G. K., D. E. Klimas, D. T. Gwynne and S. K. Sakaluk. 1989. Virgin male mating advantage in a primitive acoustic insect (Orthoptera: Haglidae). J. Insect Behav. 2:173-185.

Sakaluk, S. K., G. K. Morris, and W. A. Snedden. 1987. Mating and its effect on acoustic signalling behaviour in a primitive orthopteran, Cyphoderris strepitans (Haglidae): the cost of feeding females. Behav. Ecol. Sociobiol.21:173-178.

Sakaluk, S. K., and W. A. Snedden. 1990. Nightly calling durations of male sagebrush crickets, Cyphoderris strepitans: size, mating and seasonal effects. Oikos 57:153-160.

Vickery, V. R. 1989. The biogeography of Canadian Grylloptera and Orthoptera. Can. Ent. 121:389-424.

Walker, T. J. 1989. Natural history. pp. 1-42. In: Cricket Behavior and Neurobiology, ed. by F. Huber, T. E. Moore and W. Loher. Cornell University Press, Ithaca, NY. 